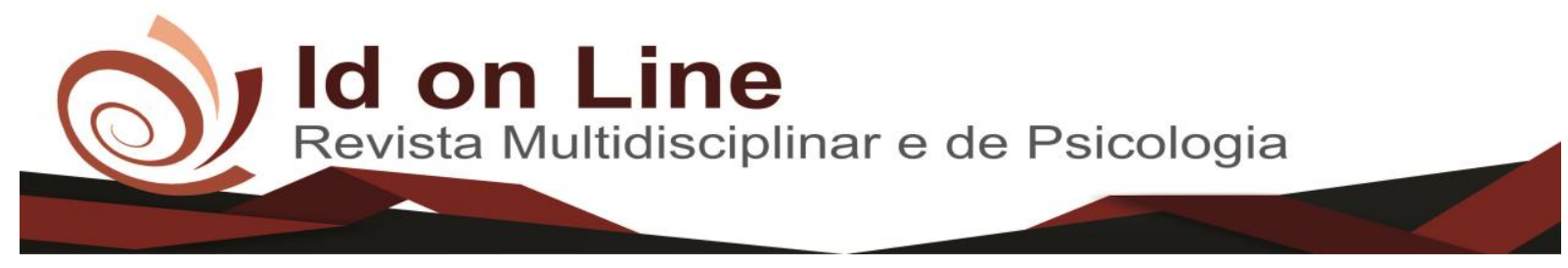

Artigo

\title{
Aplicação do Modelo Box-Jenkins na Previsão da Produção de Automóveis
}

\author{
Séfora Laissa Alcântara Pereira ${ }^{l}$; José Eduardo de Carvalho Lima
}

Resumo: O setor automotivo executa um papel indispensável para o crescimento de um país cabido a sua eficácia integrada. Ultimamente, o setor automobilístico vem passando por momentos cíclicos, gerando complicações no planejamento de ações. Por isso, tem sido um objeto de estudo direcionado tanto para procedimentos de propagação e produção, quanto para a contribuição na atuação de decisões. Com isso, apresenta uma necessidade de prever sua produção por obter influência no favorecimento de resoluções viáveis. O presente artigo tem como objetivo analisar um modelo de previsão de séries temporais por meio da metodologia Box-Jenkins, que se adeque às características da produção do setor automotivo, com o intuito da realização da previsão de produção de automóveis brasileiros. Foi utilizada uma série de produção mensal em recorte temporal de 2007 a junho de 2018 com dados da ANFAVEA, concluindo o modelo mais apto: SARIMA $(1,0,0)(1,0,0)$, com tendência desfavorável, conforme crises ocorridas atualmente.

Palavras chave: Previsão. ARIMA. Setor de Automotivo.

\section{Application of the Box-Jenkins Model in the Automobile Production Forecast}

\begin{abstract}
The automotive sector plays an indispensable role for the growth of a country based onits integrated effectiveness. Lately, the automotive sector has been going through cyclical times, generating complications in the planning of actions. Therefore, it has been an object of study directed both to propagation and production procedures, as well as to the contribution in the performance of decisions. With this, it presents a need to predict its production by gaining influence in the favoring of viable resolutions. The purpose of this paper is to analyze a time series prediction model using the Box-Jenkins methodology, which fits the characteristics of the production of the automotive sector, with the aim of realizing the forecast of production of Brazilian automobiles. A series of monthly production was used in a temporal cut from June 2007 to June 2018 with data from ANFAVEA, concluding the most suitable model: SARIMA $(1.0,0)(1.0,0)$, with unfavorable trend, according to crises occurred currently.occur.
\end{abstract}

Keywords: Prediction. ARIMA. Automotive Sector.

\section{Introdução}

A indústria automobilística percorreu por uma etapa de crescimento hiperativo entre as décadas de 50 e 70, posteriormente obteve uma estação de baixa produção, enquanto outros países realizavam

\footnotetext{
${ }^{1}$ Graduanda do curso de administração de empresas, Centro Universitário Doutor Leão Sampaio/Unileão - Juazeiro do Norte - CE, sefora_laissa@hotmail.com

${ }^{2}$ Professor orientador do Centro Universitário Doutor Leão Sampaio/Unileão - Juazeiro do Norte - CE, Mestre em Economia do Setor Público pela Universidade Federal do Ceará e Doutorando em Engenharia de Produção e Sistemas pela Universidade do Vale do Rio dos Sinos, joseduardo@leaosampaio.edu.br
}

1073 Id on Line Rev. Mult. Psic. V.12, N. 42, p. 1073-1097, 2018 - ISSN 1981-1179

1073 Edição eletrônica em http://idonline.emnuvens.com.br/id 
investimentos para atender ao mercado consumidor (FLIGENSPAN, 2002). No desfecho do século XX, a indústria passou por grandes modificações, incentivada pela tecnologia. Com isso, a dinâmica de automóveis brasileiros voltou a crescer e com a elevação dos investimentos no auge do ano de 1990 ao início do ano 2000, a eficiência produtiva brasileira aumentou e fez com que o país atingisse a sexta posição na produção mundial de veículos. (TORRES, 2013; ASTOLPHI, 2018).

Nos últimos anos, a indústria automotiva no Brasil percorreu momentos cíclicos, gerando complicações no planejamento de ações. A desvalorização cambial e a reparação da economia brasileira favoreceram para que o Brasil registrasse um saldo positivo em suas operações de comércio exterior (ZUCOLOTO; GIAROLA; ROCHA, 2018). A Associação Nacional dos Fabricantes de Veículos Automotores (Anfavea) afirma que em janeiro de 2017, o Brasil obteve a melhor marca em exportações desde 2008. Foram vendidos ao exterior 37.189 veículos montados, representando uma elevação de 56\%, comparando ao mesmo mês em 2016.

O setor automobilístico possui uma enorme importância na economia, recebendo incentivos e estímulos do governo, pois este setor industrial expande a cada dia seus próprios suportes de fabricação sobre novas relações de marketing, sobre sistemas de respostas aceleradas à busca econômica, e sobre alianças internacionais com base em reciprocidades de mercados, produtos e competências, a edificação de cenários é usualmente bem-vinda pelos empresários. Isso pode dar-lhes alguns utensílios para tomar decisões que facilite e permita a antecipação das tendências de mercado por algumas décadas. E para o futuro próximo, esta capacidade de antecipação e de prospectiva será entendida como uma ferramenta de gestão competitiva (MONIZ, 2007).

O enorme destaque do ramo também pode ser compreendido através da matriz insumo-produto fazendo uma pequena simulação: considerando um carro popular no valor de $\mathrm{R} \$ 30.000,00$ gera um produto adicional no valor de $\mathrm{R} \$ 72.000,00$, ou seja, mais que o dobro. Pesquisas demonstram que a cada carro vendido assegura emprego para mais de 1 milhão de pessoas. Dessa forma, a demanda incluída de um carro, proporciona efeitos para todos os setores econômicos.

Hoje em dia, o predomínio das montadoras internacionais de elevados aspectos detém sua sede no Brasil, além da indústria automotiva apresentar 5\% do PIB do país. A operação de automóveis tem sido um objeto de estudo direcionado tanto para procedimentos de propagação e produção, quanto para a contribuição na tomada de decisões, por cumprir um papel apontado para a progressão nacional (DE SALES, 2018). Assim, a temática tem como problemática a relação do impacto da crise, juntamente com a variação existente na produção de automóveis, tornando-se uma dificuldade para prever a sua produção.

Walter et al. (2010) investigaram em seu trabalho a utilização dos procedimentos ideais, abordando também a previsão de produção relacionado aos automóveis. Eles concluíram que os padrões 
das séries periódicas, baseados na metodologia Box e Jenkins, é provavelmente uma boa alternativa correspondente a previsões do consumo de automóveis.

Assim, considerando a importância dos modelos de previsão aplicados a séries de tempo e o setor automotivo brasileiro, o artigo tem como objetivo analisar um modelo de previsão de séries temporais por meio da metodologia Box-Jenkins, que se adeque às características da produção do setor automotivo, com o propósito da realização da previsão de produção de automóveis em todo o país, verificando estatisticamente se o modelo é apropriado para se realizar a previsão através de seus dados históricos.

Inicialmente se estabelece uma breve descrição abordando os temas séries temporais, previsão de demanda, modelo ARIMA, e os indicadores de erros e critérios de avaliação de uma previsão, em seguida apresentam-se os procedimentos metodológicos para previsão da produção e, por fim, a análise dos resultados e considerações finais.

\section{Referencial Teórico}

\section{Séries Temporais}

Entende-se por séries temporais, um conjunto histórico de observações no tempo, fundamentadas na concepção de que os acontecimentos passados podem ser usados para prever o futuro (MAKRIDAKIS; WHEELWRIGHT; HYNDMAN, 1998; KITAGAWA, 2010). A principal característica inerente aos métodos de séries temporais é que usam o comportamento passado da variável de um único fenômeno ao longo do tempo e, baseada nele fazem previsões. (SLACK; JONES; JOHNSTON, 2015).

Walter et al. (2013) ressalta que os métodos estatísticos de previsão das séries de tempo, procuram especificar o padrão da conduta da série, utilizando-o para prever valores futuros. Portanto, a série temporal pode ser apresentada como sendo um conjunto de análises de uma variável observada consequentemente no tempo (BOX; JENKINS, 1976; FELIPE, 2012; FIGUEIREDO; BLANCO, 2014). Dessa forma, como os dados são coletados com o decorrer do tempo, tem-se uma expectativa que a série mostre uma correlação ordenada no período (WERNER; RIBEIRO, 2003).

Quando se fala em análise de série temporal, deve-se primeiro adaptar o fenômeno avaliado para consequentemente descrever o comportamento ou conduta da série, além de definir as estimativas e fatores que influenciam nesse comportamento da série (LATORRE; CARDOSO, 2001; CERETTA; RIGHT; SCHLENDER，2010; FELIPE; 2012). A análise tem como objetivo compreender o 
instrumento que produz a série, identificando medidas não aleatórias, além de prever seu futuro comportamento, obtendo o menor erro possível (CERETTA; RIGHI; SCHLENDER, 2010).

Em uma série temporal, a variável analisada é vista em intervalos de tempos equidistantes e a sua correlação entre diferentes pontos da série apresenta-se a característica de necessidade entre eles, (LOURENÇO; NASCIMENTO, 2012). Desta maneira, compreende-se que a série temporal pode ser apresentada como sendo as prováveis relações de determinados processos. Portanto, Ribeiro e Paula (2016) afirmam que a série temporal também pode ser observada como uma série estocástica, ou seja, retrata de acontecimentos indeterminados ou aleatórios.

\section{Previsão de Séries Temporais}

A previsão de uma série temporal é definida A determinação de valores que irão acontecer futuramente em uma sequência, ou seja, uma antecipação desses valores a partir de dados coletados atualmente é definida (CRYER; CHAN, 2008; MOURA, 2018). Todavia, Bowersox e Closs (2010) destacam que as predições são quantidades que possivelmente serão produzidas, vendidas e destinadas ou até mesmo podem ser definidas como ressalto de valores.

Essas previsões com base em séries históricas surgem a partir de um processo futuro, sendo ela uma projeção de valores passados, além de ser identificado como um método simples e com bons resultados se elaborado corretamente (TUBINO, 2017). Pindyck e Rubinfeld (2004) apontam que os modelos de previsões de séries temporais podem ser classificados em dois tipos, sendo eles: modelos determinísticos e modelos estocásticos.

Os modelos determinísticos são aqueles em que em sua elaboração não apresentam uso de variáveis aleatórias, ou seja, são estimativas exatas, já o estocástico é aquele cujo estado é indeterminado, exibindo resultados aleatórios (PELLEGRINI, 2000; SILVA, 2008). Os modelos estocásticos são apropriados quando são efetuados em séries estacionárias, sendo que o sistema estocástico se torna estacionário se a média e variância mantêm-se constantes no decorrer do tempo (CAMPOS; CLEMENTE; CORDEIRO, 2006).

Modelo Arima (p, d, q)

Os modelos de Box-Jenkins foram desenvolvidos com o intuito de compreender o comportamento da autocorrelação, ou seja, as correlações das séries. Assim, buscando entender os valores entre a série temporal e a realização de previsões que tem sua referência no comportamento. Essa 
metodologia mostra a identificação ou ajustes de moldes auto regressivos integralizados à média móvel, como o modelo ARIMA (SOUZA, 2006). Lee e Ko (2011) concordam que esse tipo de metodologia é uma das mais utilizadas em séries temporais, por conta de sua generalidade. É significativo salientar que esse método estabelece seus limites de utilidade de no mínimo 100 observações por preferência (CERETTA; RIGHI; SCHLENDER, 2010)

Uma dos recursos primordiais desse tipo de metodologia é converter uma série não estacionária em uma outra estacionária, cujo o reconhecimento é mais facilitada, pois irá adquirir a segurança dos indicadores avaliados (SÁFADI, 2004; FELIPE, 2012). Os modelos ARIMA (p,d,q) é consequência da ligação de três componentes: o modelo autoregressivo (AR), médias móveis (MA) e da combinação desses dois componentes formando o ARMA (MARTIN et al., 2016).

$\mathrm{O}$ modelo $\mathrm{AR}(\mathrm{p})$ tem como componente p que corresponde a uma ordem máxima desse método, tendo a função de afeiçoar a conexão de valores atuais com os valores do passado (FERRO, 2018; DE SALES et al. 2018). Walter et al. (2013) ainda acrescenta que o AR apresenta um ruído aleatório. O modelo auto regressivo é representado pela seguinte equação (MORETTIN; TOLOI, 2004; LEE; KO, 2011; SANTILI, 2015):

$$
\mathrm{Z}_{\mathrm{t}}=\phi_{1} \mathrm{Z}_{\mathrm{t}-1}+\phi_{2} \mathrm{Z}_{\mathrm{t}-2}+\ldots+\phi_{\mathrm{p}} \mathrm{Z}_{\mathrm{t}-\mathrm{p}}+\mathrm{a}_{\mathrm{t}}
$$

Onde p é ordem de $A R, Z_{t}$ representa a série temporal notado no momento t e $a_{t}$ é o ruído aleatório com um ordenamento padrão, no qual a sua média será 0 e a sua variância 1 e $\phi_{1}, \ldots . ., \phi_{\mathrm{p}}$ são parâmetros do modelo auto regressivo. Lee e Ko (2011) testificam que ao acrescentar o lag B, o modelo consegue ser redigido pela fórmula a seguir:

$$
\phi_{\mathrm{p}}(\mathrm{B})=1-\phi_{1} \mathrm{~B}-\phi_{2} \mathrm{~B}^{2}-\ldots-\phi_{p} \mathrm{~B}^{p}
$$

Com isso, a fórmula 1 pode ser resumida em $\phi_{\mathrm{p}}(\mathrm{B}) Z_{t}=a_{\mathrm{t}}$, em que $\phi(\mathrm{B})$ é o executor de $\mathrm{AR}(\mathrm{p})$.

Para Ferro (2018) no modelo MA(q), o $q$ também corresponde a uma ordem máxima, sendo que referente ao modelo MA, atribuindo que os valores passados são dependentes de erros previstos nos períodos anteriores. Este modelo decorre da fusão de ruídos brancos e do período atual com aqueles que ocorreram anteriormente (WERNER; RIBEIRO, 2003).

De acordo com Morettin e Toloi (2004), Lee e Ko (2011) e Santili (2015), o modelo é apresentado pela equação:

$$
\mathrm{Z}_{\mathrm{t}}=\mathrm{a}_{\mathrm{t}}-\theta_{1} \mathrm{a}_{\mathrm{t}-1}-\theta_{2} \mathrm{a}_{\mathrm{t}-2}-\ldots-\theta_{\mathrm{q}} \mathrm{a}_{\mathrm{t}-\mathrm{q}}
$$

Podendo assim como o AR, ser reescrito como: $Z_{\mathrm{t}}=\theta_{\mathrm{q}}(\mathrm{B}) \mathrm{a}_{\mathrm{t}}$. Nesse caso o $q$ é a ordem de $\operatorname{MA}(\mathrm{q}), \phi_{1}, \ldots . ., \phi_{\mathrm{q}}$ seus indicadores. $\theta_{\mathrm{q}}(\mathrm{B})$ é estabelecido por $\theta_{\mathrm{p}}(\mathrm{B})=1-\theta_{1} \mathrm{~B}-\theta_{2} \mathrm{~B}^{2}-\ldots-\theta_{\mathrm{q}} \mathrm{B}^{\mathrm{q}}$. As equações reescritas nos modelos AR e MA são agregadas para formar o modelo ARMA (p,q) (WALTER et al. 2013):

$$
\phi(\mathrm{B}) Z_{t}=\theta_{\mathrm{q}}(\mathrm{B}) \mathrm{a}_{\mathrm{t}}
$$


Os modelos AR, MA e ARMA são utilizados em séries estacionárias (GUJARATI; PORTER, 2011). Quando a série apresenta um comportamento não estacionário, a diferenciação " $d$ ” tem como função transformá-la em uma série estacionária (MARTIN et al., 2016; FERRO, 2018). Com isso, Walter et al. (2013) discute que nos três modelos citados acima (AR, MA e ARMA) é utilizado o componente de integração I(d) para formar o ARIMA, representado por:

$$
\phi_{\mathrm{p}}(\mathrm{B}) \Delta^{\mathrm{d}} \mathrm{Z}_{\mathrm{t}}=\theta_{\mathrm{q}}(\mathrm{B}) \mathrm{a}_{\mathrm{t}}
$$

Na equação citada acima $d$ é a ordem de diferença e, sendo $\Delta^{\mathrm{d}} \mathrm{Z}_{\mathrm{t}}=(1-\mathrm{B})^{\mathrm{d}} \mathrm{Z}_{\mathrm{t}}$, no qual $\Delta^{\mathrm{d}}$ ou $(1-$ B) dé dado como a computação de diferenças necessários para tornar a série estacionária. Em resumo, o ARIMA é resultado da conciliação de três elementos denominados "filtros": AR(p), I(d) e MA(q) (MARENGUE, 2017).

Existe ainda outro tipo de modelo conhecido como SARIMA (p, d, q)(P, D, Q), o diferencial está no "S" induzindo que há uma sazonalidade no modelo. Os parâmetros (p,d,q) representam a natureza da série temporal em si, já o $(\mathrm{P}, \mathrm{D}, \mathrm{Q})$ as características da sazonalidade do evento, tendo como fórmula (BOX e JENKINGS, 1976):

$$
\phi_{\mathrm{p}}(\mathrm{B}) \phi_{\mathrm{p}}\left(\mathrm{B}^{\mathrm{s}}\right) \Delta^{\mathrm{d}} \Delta_{\mathrm{s}}^{\mathrm{D}} \mathrm{Z}_{\mathrm{t}}=\theta_{\mathrm{q}}(\mathrm{B}) \Theta_{\mathrm{Q}}\left(\mathrm{B}^{\mathrm{s}}\right) \mathrm{a}_{\mathrm{t}}
$$

No qual $\Delta_{\mathrm{s}}^{\mathrm{D}} \mathrm{Z}_{\mathrm{t}}=\left(1-\mathrm{B}^{\mathrm{s}}\right){ }^{\mathrm{D}} \mathrm{Z}_{\mathrm{t}}$, sendo $\mathrm{D}$ a ordem de diferenciação sazonal, $\phi_{\mathrm{p}}\left(\mathrm{B}^{\mathrm{s}}\right)$ é executor sazonal $\mathrm{AR}(\mathrm{p})$ estipulado por $\phi_{\mathrm{p}}\left(\mathrm{B}^{\mathrm{s}}\right)=1-\phi_{1}\left(\mathrm{~B}^{\mathrm{s}}\right)-\phi_{2}\left(\mathrm{~B}^{2 \mathrm{~s}}\right)-\ldots-\phi_{\mathrm{p}}\left(\mathrm{B}^{\mathrm{ps}}\right) ; \Theta_{\mathrm{Q}}\left(\mathrm{B}^{\mathrm{s}}\right)$ é o executor sazonal MA(q) por $\Theta_{\mathrm{Q}}\left(\mathrm{B}^{\mathrm{s}}\right)=1-\Theta_{1}\left(\mathrm{~B}^{\mathrm{s}}\right)-\Theta_{2}\left(\mathrm{~B}^{2 \mathrm{~s}}\right)-\ldots-\Theta_{\mathrm{Q}}\left(\mathrm{B}^{\mathrm{Qs}}\right)$, e $\phi_{1}, \ldots \phi_{\mathrm{P}}, \Theta_{1}, \ldots \Theta_{\mathrm{Q}}$ são referências do modelo sazonal $\mathrm{AR}(\mathrm{p})$ e $\mathrm{MA}(\mathrm{q})$ respectivamente.

Como dito antes, o Modelo Box e Jenkins é um método popular, por isso é muito utilizado em séries temporais. Entretanto, muitos autores utilizaram esse modelo para fazer predições em vários tipos de setores, observados na Tabela 1.

\begin{tabular}{|c|c|c|c|}
\hline AUTOR & SETOR & OBJETIVO & ACHADOS \\
\hline $\begin{array}{l}\text { LEITE et al. } \\
\qquad(2013)\end{array}$ & $\begin{array}{l}\text { Parâmetros de índice } \\
\text { de qualidade de água }\end{array}$ & $\begin{array}{l}\text { Avaliar de formar isolada a } \\
\text { inclinação de cada } \\
\text { paaâmetro associado a } \\
\text { cálculos do índice de } \\
\text { Qualidade de água (IQA). } \\
\text { Para isso, o ARIMA foi } \\
\text { utilizado para seleção dos } \\
\text { parâmetros que influenciam } \\
\text { essencialmente o IQA. }\end{array}$ & $\begin{array}{l}\text { O ARIMA facilitou uma melhor } \\
\text { compreensão dos parâmetros } \\
\text { físicos, químicos e biológicos. Com } \\
\text { isso, influenciou na comprovação } \\
\text { do IQA. }\end{array}$ \\
\hline $\begin{array}{l}\text { WALTER et } \\
\text { al.(2013) }\end{array}$ & $\begin{array}{l}\text { Previsão de vendas } \\
\text { de motocicletas }\end{array}$ & $\begin{array}{l}\text { Averiguar um método de } \\
\text { previsão de rendas, } \\
\text { fundamentado } \\
\text { metodologia Box e Jenkins }\end{array}$ & $\begin{array}{l}\text { A conclusão obtida é que o modelo } \\
\text { SARIMA é uma opção acessível } \\
\text { para a série analisada. }\end{array}$ \\
\hline & & & $\begin{array}{l}\text { As respostas adquiridas concedem } \\
\text { uma metodologia de análise para o }\end{array}$ \\
\hline
\end{tabular}

Tabela 1 - Aplicabilidade do Modelo Box e Jenkins em vários ramos 


\begin{tabular}{|c|c|c|c|}
\hline CAS (2018) & $\begin{array}{l}\text { Previsão do preço da } \\
\text { commodity milho }\end{array}$ & $\begin{array}{l}\text { Observar a conduta dos } \\
\text { preços médios recebidos } \\
\text { pelo produtor da } \\
\text { commodity } \quad \text { milho } \\
\text { brasileira, realizando sua } \\
\text { previsão a partir do método } \\
\text { ARIMA. }\end{array}$ & $\begin{array}{l}\text { mercado desta commodity, onde } \\
\text { comprovam uma inclinação dos } \\
\text { preços para uma perspectiva de } \\
\text { curto prazo, dando assistência no } \\
\text { auxílio à tomada de decisão de } \\
\text { operadores que comercializam este } \\
\text { bem. }\end{array}$ \\
\hline FERRO (2018) & $\begin{array}{l}\text { Previsão de venda } \\
\text { de Eletrodomésticos }\end{array}$ & $\begin{array}{l}\text { Garantir um procedimento } \\
\text { para prever a venda de } \\
\text { eletrodomésticos } \mathrm{em} \\
\text { indústrias do ramo de ala } \\
\text { branca, através da } \\
\text { agregação de métodos } \\
\text { qualitativos e quantitativos, } \\
\text { como o ARIMA. }\end{array}$ & $\begin{array}{l}\text { Os resultados focalizam apenas na } \\
\text { melhoria da família alfa, mas } \\
\text { quando conciliada as demais } \\
\text { famílias beta e gama } \\
\text { respectivamente não houve o } \\
\text { mesmo resultado. Além disso, com } \\
\text { a aplicação do método, houve } \\
\text { redução do MAPE. }\end{array}$ \\
\hline SOKI (2018) & $\begin{array}{l}\text { Previsão da taxa de } \\
\text { Inflação }\end{array}$ & $\begin{array}{l}\text { Comparar tanto os } \\
\text { seguimentos adquiridos ao } \\
\text { modelar as séries, quanto a } \\
\text { previsão das taxas de } \\
\text { inflação mensal. }\end{array}$ & $\begin{array}{l}\text { O modelo ARMA é mais favorável } \\
\text { em relação a antecipação, sendo } \\
\text { igual para taxas de inflações } \\
\text { mensais e taxa de inflação } \\
\text { adotadas, utilizando-se de variáveis } \\
\text { externas. }\end{array}$ \\
\hline
\end{tabular}

Fonte: Elaborado pelo autor (2018)

Como visto na tabela acima, foram dados oito exemplos de aplicação do modelo ARIMA indicando uma alta efetividade com relação a todos os tipos de segmentos, obtendo uma facilidade de implementação e sendo ainda um poderoso procedimento para previsões de curto prazo.

\section{Etapas do Modelo Box E Jenkins}

Segundo Box e Jenkins (1976), a construção do modelo ARIMA envolvem quatro etapas: a identificação do modelo, estimativa do modelo, verificação do diagnóstico e a previsão. Essas etapas podem ser vistas na figura 1 (GUJARATI, 2011):

Figura 1 - Etapas do Modelo Box e Jenkins

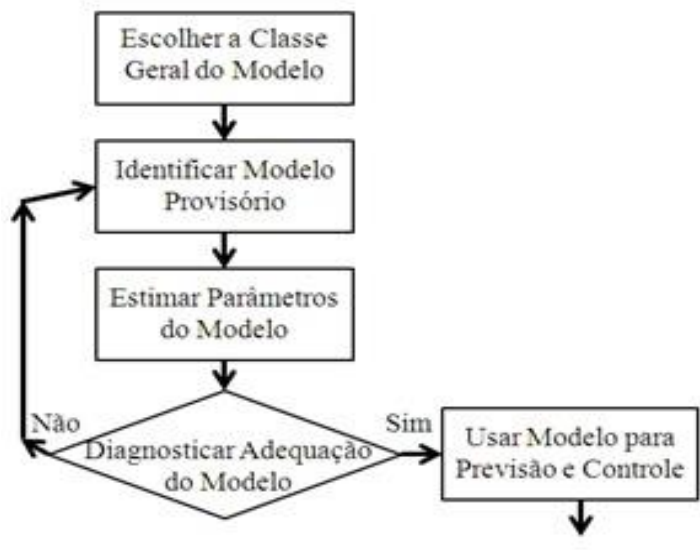

Fonte: Senna et al. (2014) 
No processamento de identificação é onde se estabelece qual o método mais apropriado. O reconhecimento dos valores inteiros das ordens $\mathrm{p}$, d e q é elaborado por intermédio das funções de Auto correlação (FAC) e da Auto correlação parcial (FACP) (SOUZA; SOUZA; LOPES, 2009; SOKI, 2018; CAS, 2018). Rajaprasad (2018) menciona que a seleção do melhor modelo depende dessas funções. O FAC é utilizado para distinguir o primeiro parâmetro $p$ que é o grau de diferenciação fundamental para estabilizar os dados, expondo seus valores em relação aos lags, já o FACP identifica o parâmetro $p$ (RIBEIRO; PAULA, 2016).

Leite et al. (2013) destaca que a identificação do modelo ARIMA corresponde a estipulação do nível de diferenciação “ $d$ ”, que torna a série estacionária. Do ponto de vista de Lucas et al. (2009), outro ponto a ser investigado nessa etapa é a quantidade de parâmetros, pois quanto maior a quantidade, mais erros podem aparecer no processo.

Logo após a determinação da ordem (p,d,q) efetuada na identificação, ocorre a estimativa do modelo que está ligada na determinação dos parâmetros auto regressivos e de média móveis por meio de suas estatísticas (GOMES, 1989; CAS, 2018). O ruído aleatório é uma importante definição a ser retratada, sendo tudo aquilo que o modelo avaliado não conseguiu conduzir ou captar (MOURA, 2018). Logo, o ruído branco é considerado como uma sequência de valores com média zero, variância constante e auto correlação igual a zero (SANTOS, 2018).

Existe ainda a verificação do diagnóstico, onde verifica se o modelo estimado está adequado à série, tendo como base os resíduos do modelo, devendo obter um procedimento no qual é constatado como ruído branco. Contudo, os níveis da auto correlação devem ser iguais a zero (SOUZA; SOUZA; LOPES, 2009). Nesse procedimento a análise de resíduos tem como intuito estabelecer um comportamento de ordem normal, ou seja, como um ruído branco (WALTER et al., 2013). Onde os resíduos representam a diferença da série original e a série prevista, podendo ser chamado de erro aleatório (SILVA, 2017).

Com todas as três etapas concluídas, realiza-se a previsão, no qual deve ser testado o modelo escolhido por meio de simulações (CAMPOS; CLEMENTE; CORDEIRO, 2006). Gujarati e Porter (2011) relata que a popularidade do modelo ARIMA, provém de sua conquista nessa fase e que na maioria das situações, as previsões possuem maior segurança através desse método, atribuindo maior confiança se comparada com métodos tradicionais.

Essa sequência pode ser considerada como um ciclo iterativo, pois caso o modelo não seja adequado, o ciclo irá se repetir (SOUZA, 2006). Um obstáculo que se encontra nesse método é que ele necessita da utilização de programas apropriados (MORETIN e TOLOI, 1981). Com isso, fica evidente 
a importância da habilidade de identificação de estacionariedade (CAMPOS, CLEMENTE, CORDEIRO, 2006).

\section{Indicadores de Erros e Critérios de Avaliação de uma Previsão}

Os modelos de previsão em geral apresentam uma incerteza, no qual é apropriado a sua modelagem. Para isso, existem inúmeros índices para medir os erros da previsão e seus critérios de seleção (RIBEIRO; PAULA, 2016). Um dos mais conhecidos é o critério de informação de Akaike, nomeado AIC, mas há outros critérios que deriva do AIC, como o Bayesian Information Criterion (BIC) que penaliza a inclusão dos parâmetros adicionais com mais rigor (EHLERS, 2009).

De acordo com Silva (2017), o BIC é utilizado na fase de verificação, com o objetivo de indicar qual o modelo mais ponderado ou adequado, ou seja, com menor número de parâmetros. O BIC também é conhecido como Critério de Schwarz, a fim de escolher o modelo em termos de probabilidade e é expresso pela fórmula (AMORIM, 2014; EHLERS, 2009):

$$
\mathrm{BIC}=-2 \log \text { verossimilhança maximizada }+m \log n
$$

Onde $\mathrm{m}$ é o apuramento de indicadores a serem estimados e $\mathrm{n}$ o número de observações. $\mathrm{O}$ n apresentado na fórmula deve ser mantido fixo, para ser feito a exploração dos modelos (SANTOS; 2014).

Carlin e Louis (2000) define que o BIC é aplicado considerando a espessura dos parâmetros do modelo reparado. Esse preceito tem a precisão de ser utilizado em companhia com as autocorrelações, sendo um complemento e não uma alternativa (SOUZA, 2006). Vale ressaltar que a comparação dos modelos deve ocorrer no mesmo período da amostra (EHLERS, 2009). Amorim (2014) menciona que o modelo exibido com o menor valor do BIC, é identificado como o mais favorável.

No andamento de modelagem da série, pode-se obter outro modelo além do ARIMA que analise diferentes normas na investigação do diagnóstico, tornando difícil a escolha do melhor modelo. Por isso, é adequado utilizar critérios na preferência do modelo fundamentado nos resíduos do modelo apropriado, como o BIC (SOKI, 2018). Cabe destacar que esse tipo de critério não deve ser operado isoladamente, mas de forma associada com outros parâmetros ao comparar modelos (LOURENÇO; NASCIMENTO, 2012).

Com relação a medidas de erros é importante enfatizar dois tipos de indicadores utilizados no meio estatístico: o MAD e o MAPE, esclarecidos nos próximos itens. Segundo Pellegrini (2000) e Silva (2008) a seleção do modelo adequada são feitas consoante o somatório dos erros elaborado, sendo destinado cada modelo. 
O MAD (Mean Absolute Deviation) mede a dispersão dos erros de previsão do componente aleatório e apresenta a acurácia na mesma unidade da informação, o que facilita o entendimento gerencial do impacto do erro de previsão. Se o MAD é pequeno, a previsão está próxima do valor real da demanda (SANTILI, 2015).

$$
\mathrm{MAD}=\frac{\sum_{\mathrm{t}=1}^{\mathrm{n}}\left|\mathrm{E}_{\mathrm{t}}\right|}{\mathrm{n}}
$$

onde $\mathrm{n}=$ número de valores coletados e $\mathrm{E}_{\mathrm{t}}$ são os erros reconhecidos.

O indicador corresponde a previsão do MAPE de forma idêntica, entretanto nas mesmas unidades que os dados (MARENGUE, 2017)

\section{Erro Absoluto Médio Percentual - MAPE}

O MAPE (Mean Absolute Percent Error) revela a acurácia da previsão como uma porcentagem. Relaciona o erro da previsão ao nível de demanda. É útil, pois permite a comparação entre previsões independente dos dados. (WALTER et al., 2010; SANTILI, 2015).

$$
\text { MAPE }=\frac{\sum_{\mathrm{t}=1}^{\mathrm{n}}\left|\frac{\mathrm{E}_{\mathrm{t}}}{\mathrm{D}_{\mathrm{t}}}\right| 100}{\mathrm{n}}
$$

onde $\mathrm{D}_{\mathrm{t}}=$ valor da demanda real no período $\mathrm{t}$.

Dentre as formas de medida de erro, o MAPE é considerado popular com relação a avaliação da exatidão de previsões. Apesar disso, é importante a verificação de valores das séries, pois quando são iguais a zero, o uso das fórmulas se torna inviável (PELLEGRINI, 2000).

\section{Método}

A metodologia utilizada para o desenvolvimento deste trabalho quanto à sua natureza foi a básica, pois além de fornecer novos conhecimentos para o crescimento no meio científico, não é preciso uma aplicação prática. Referente aos objetivos foi escolhido o método exploratório, já que proporciona informações investigadas com a aptidão na determinação do tema (SEVERINO, 2016).

O presente trabalho é de caráter bibliográfico, desenvolvendo o estudo através de consultas a referências de livros, base de dados e publicações periódicas atuais sobre a temática como forma de 
fundamentação teórica (PRODANOV; FREITAS, 2013). Pode ser apresentada também como uma pesquisa documental, pois tem o documento como objeto de identificação, além de ultrapassar a ideia de textos escritos (SÁ-SILVA, 2009).

A abordagem é de gênero quantitativo, utilizando técnicas de modelagem estatística para sua realização com o recolhimento e análise dos dados. Com isso, para o presente estudo, primeiramente aderiu-se um levantamento de dados, coletada a partir da base de dados da Associação Nacional dos Fabricantes de Veículos Automotores (Anfavea), utilizando uma série temporal, cuja base de dados é apresentada na Tabela 2, contendo 138 observações, dentro de um recorte temporal de janeiro de 2007 à junho de 2018.

Tabela 2 - Produção de Automóveis nos períodos 2007 - 2018

\begin{tabular}{|c|c|c|c|c|c|c|c|}
\hline Período & $\begin{array}{c}\text { Produção } \\
\text { (unid.) }\end{array}$ & Período & $\begin{array}{l}\text { Produção } \\
\text { (unid.) }\end{array}$ & Período & $\begin{array}{c}\text { Produção } \\
\text { (unid.) }\end{array}$ & Período & $\begin{array}{c}\text { Produção } \\
\text { (unid.) }\end{array}$ \\
\hline 1 & 161605 & 36 & 193516 & 71 & 257468 & 106 & 165763 \\
\hline 2 & 159393 & 37 & 186269 & 72 & 220589 & 107 & 143934 \\
\hline 3 & 195931 & 38 & 188222 & 73 & 238063 & 108 & 123699 \\
\hline 4 & 177941 & 39 & 256006 & 74 & 190362 & 109 & 132206 \\
\hline 5 & 204063 & 40 & 216850 & 75 & 264830 & 110 & 118574 \\
\hline 6 & 193968 & 41 & 238389 & 76 & 279127 & 111 & 165544 \\
\hline 7 & 212032 & 42 & 224942 & 77 & 275798 & 112 & 142067 \\
\hline 8 & 218310 & 43 & 231938 & 78 & 257861 & 113 & 146224 \\
\hline 9 & 201543 & 44 & 243000 & 79 & 254371 & 114 & 147480 \\
\hline 10 & 236446 & 45 & 219951 & 80 & 267515 & 115 & 152295 \\
\hline 11 & 218002 & 46 & 232071 & 81 & 252575 & 116 & 149414 \\
\hline 12 & 181505 & 47 & 237519 & 82 & 253699 & 117 & 141286 \\
\hline 13 & 200764 & 48 & 207767 & 83 & 234256 & 118 & 151948 \\
\hline 14 & 197647 & 49 & 191191 & 84 & 185822 & 119 & 185640 \\
\hline 15 & 222548 & 50 & 231395 & 85 & 190993 & 120 & 166216 \\
\hline 16 & 236206 & 51 & 231412 & 86 & 223578 & 121 & 149289 \\
\hline 17 & 229493 & 52 & 221633 & 87 & 218999 & 122 & 170349 \\
\hline 18 & 242191 & 53 & 232564 & 88 & 218831 & 123 & 200123 \\
\hline 19 & 251952 & 54 & 228666 & 89 & 225128 & 124 & 157755 \\
\hline 20 & 245913 & 55 & 240457 & 90 & 170638 & 125 & 208110 \\
\hline 21 & 233650 & 56 & 252342 & 91 & 199903 & 126 & 173609 \\
\hline 22 & 225246 & 57 & 196993 & 92 & 207861 & 127 & 187771 \\
\hline 23 & 143636 & 58 & 201438 & 93 & 236856 & 128 & 219927 \\
\hline 24 & 69236 & 59 & 203719 & 94 & 229861 & 129 & 203103 \\
\hline 25 & 147345 & 60 & 199083 & 95 & 210907 & 130 & 209989 \\
\hline 26 & 165302 & 61 & 177408 & 96 & 168567 & 131 & 208540 \\
\hline 27 & 227657 & 62 & 172863 & 97 & 165383 & 132 & 180665 \\
\hline 28 & 208010 & 63 & 253426 & 98 & 165270 & 133 & 181525 \\
\hline 29 & 222104 & 64 & 218069 & 99 & 203826 & 134 & 176807 \\
\hline 30 & 233751 & 65 & 229235 & 100 & 177807 & 135 & 218015 \\
\hline 31 & 227192 & 66 & 225172 & 101 & 178335 & 136 & 216984 \\
\hline 32 & 241640 & 67 & 242272 & 102 & 158494 & 137 & 179583 \\
\hline 33 & 219626 & 68 & 269723 & 103 & 191375 & 138 & 208846 \\
\hline 34 & 252360 & 69 & 233159 & 104 & 186323 & & \\
\hline 35 & 229664 & 70 & 264061 & 105 & 147031 & & \\
\hline
\end{tabular}

Fonte: Adaptado da ANFAVEA (2018) 
A pesquisa foi composta de quatro fases determinadas na metodologia de Box-Jenkins (ARIMA): identificação do modelo, a estimativa do modelo, a verificação de diagnóstico e a realização de previsões. Sendo utilizada também a Função de Auto Correlação (FAC) e Função de Auto Correlação Parcial (FACP). O tipo de critério utilizado para avaliar o modelo para análise dos dados foi o Bayesian Information Criterion (BIC). A avaliação proposta foi incluída na fase de verificação, no qual a quantidade mínima de parâmetros seria o mais adaptado para a série.

$\mathrm{Na}$ identificação do modelo, foi verificado o modelo mais apropriado para produção do estudo com valores provisórios dos parâmetros $(\mathrm{p}, \mathrm{d}, \mathrm{q})$. Com isso, houve a estimação dos parâmetros AR e MA através de suas estatísticas. Na verificação foi observado se o modelo foi regulado à série, para finalmente ocorrer a previsão.

Por fim, foram realizadas a análise e discussão dos resultados coletados por meio do software Excel e os cálculos estabelecidos através do software livre R, disponibilizando uma intensa diversidade no meio estatístico, sendo então apropriado para o modelo ARIMA.

\section{Análise e Discussões de Resultados}

A análise foi efetuada com base nas etapas do modelo sugerido, visto na Figura 1. Para identificar o modelo propício á série, primeiramente foi elaborado o gráfico dos dados da série em estudo (Figura 2).

Figura 2 - Produção de automóveis entre o período de janeiro/2007 a junho/2018

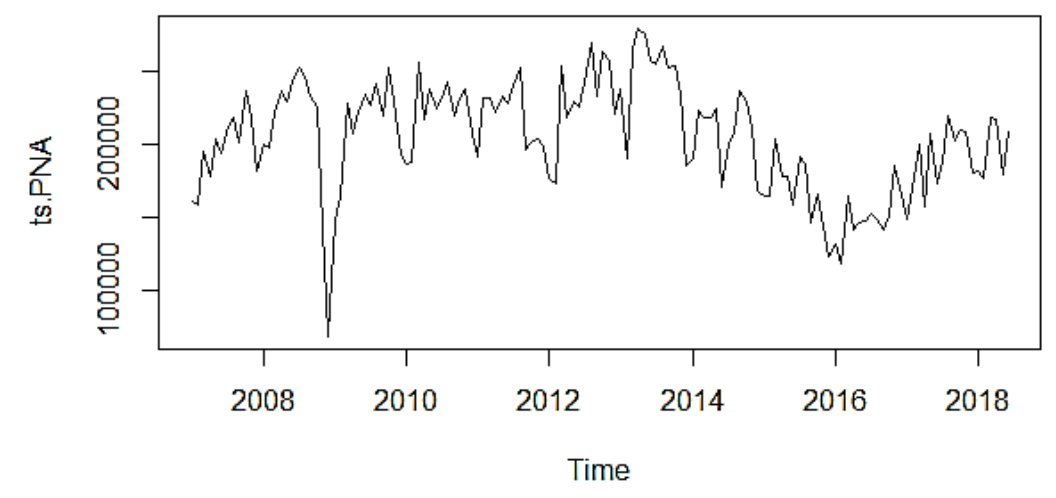

Fonte: Elaborado pelo autor (2018) 
No gráfico estabelecido com relação à periodicidade semestral da série, não há possibilidade de distinguir se a série apresenta ou não estacionariedade, pois a mesma exibe quedas em alguns intervalos de tempo o que não é típico de uma série estacionária, gerando dúvida quanto a sua classificação. Diante disso, verifica-se a comparação dos correlogramas: FAC e FACP. Através deles, será possível identificar a tendência, sazonalidade, assim como a filtragem de resíduos.

Figura 3 - Correlograma de FAC

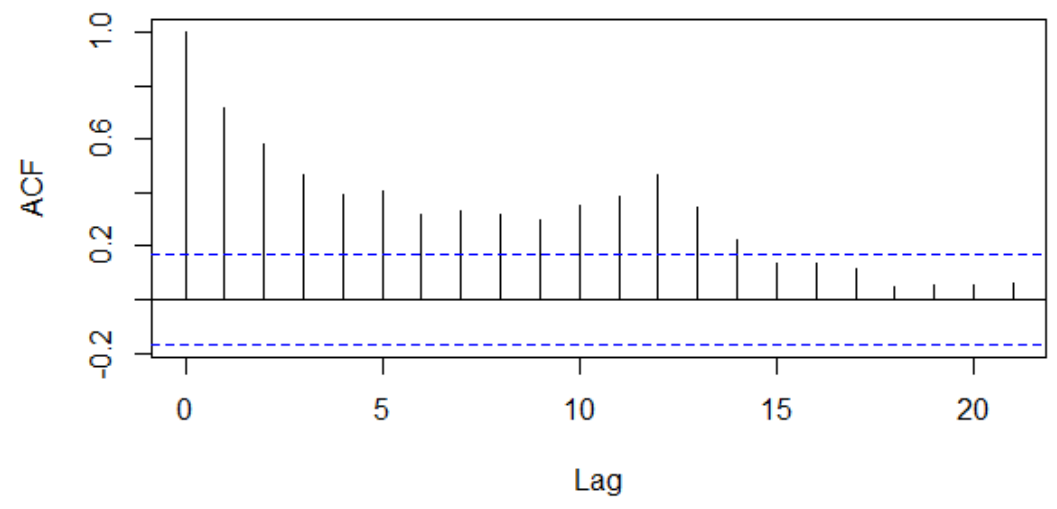

Fonte: Elaborado pelo autor (2018)

Ao observar o gráfico acima (Figura 3), percebe-se uma correlação significativa no lag1, com um padrão seguido a cada 5 defasagens além de incluir a afirmação da possibilidade de uma série não estacionária, o motivo que leva a isso é sua defasagem não cair abruptamente para zero. Nota-se também uma variação, representando um caráter sazonal. Além disso, repara-se uma autoregressividade exponencial nos pontos relatados. Dessa forma, há uma alternativa de ser um modelo AR.

Figura 4 - Correlograma de FACP

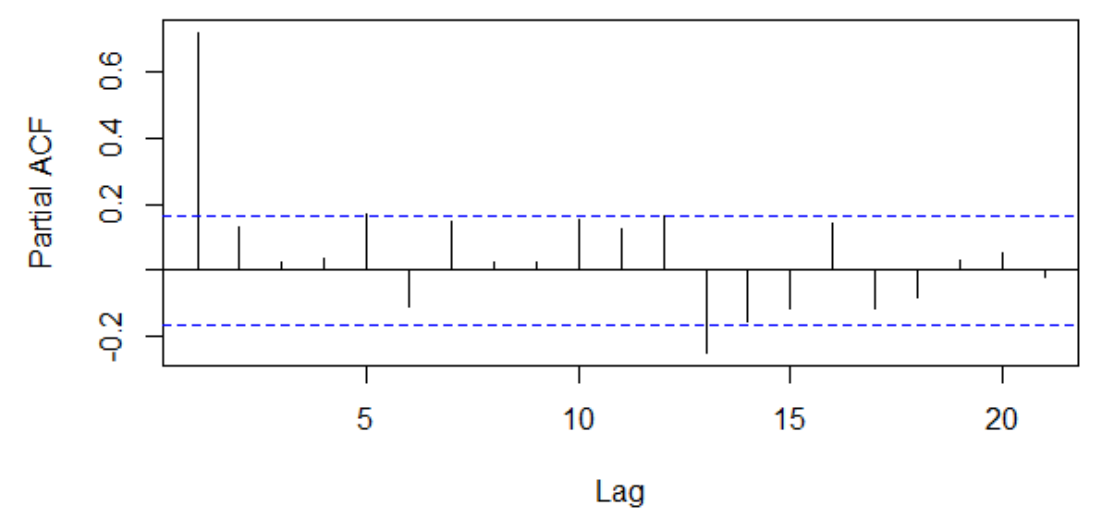

Fonte: Elaborado pelo autor (2018) 
No gráfico de FACP (Figura 4), é perceptível que há uma melhora diante dos lags supostos, mesmo podendo conter um atraso inicial, indicando que a ordem do modelo autoregressivo pode ser igual a um, ou seja, AR(1). Mesmo com o progresso da autocorrelação parcial, a série não fica clara se pode ser considerada estacionária, mas já se pode observar que não é ergódica, pois nem todos os pontos permanecem padronizados diante da amplitude ajustada.

Outro argumento deve ser cogitado para comprovar que na FACP o encadeamento tem a perspectiva de não ser estacionário, alguns elementos mostraram-se acima do limite definido $(1,5,13)$. Diversos experimentos foram utilizados analisados adiante, sendo eles: o teste de estacionariedade, normalidade, tendência e sazonalidade.

Foi adotado um grau de confiabilidade de $95 \%$ para análise dos testes e para todos eles possuem uma mesma regra: o p-valor dependerá do nível de significância de 5\%, mas cada um com suas hipóteses.

Tabela 3 - Testes de Estacionariedade

\begin{tabular}{ccc}
\hline \multicolumn{3}{c}{ Testes Estacionários } \\
\hline Testes & Estatísticas & P-valores \\
KPSS & 0,97 & 0,01 \\
Dickey - Fuller & $-4,26$ & 0,01 \\
Phillips - Perron & $-40,01$ & 0,01 \\
\hline
\end{tabular}

Fonte: Elaborado pelo autor (2018)

Para impossibilitar incertezas da estagnação serial, foram realizados três testes: o denominado KPSS, com estatística $=0,97$ e atribuição de um valor de $\mathrm{p}$ aproximadamente igual a zero, concluindo que a sequência é reconhecida como não estacionário. Nos testes Dickey-Fuller e Phillips-Perron, as estatísticas foram iguais a $-4,26$ e $-40,01$, nessa mesma ordem. Todos os testes apresentaram os mesmos valores, mas os dois últimos observados na tabela diz ser uma série estacionária por não existir raiz unitária.

Tabela 4 - Teste de Normalidade

\begin{tabular}{ccc}
\hline \multicolumn{3}{c}{ Testes de Normalidade } \\
\hline Testes & Estatísticas & P-valores \\
Anderson - Darling & 0,79 & 0,03 \\
Kolmogorov - Smirnov & 0,09 & 0,00 \\
Shapiro - Wilk & 0,97 & 0,02 \\
Ryan - Joiner & 0,98 & 0,02 \\
\hline
\end{tabular}

Fonte: Elaborado pelo autor (2018) 
De acordo com os testes realizados relacionados à normalidade, conclui-se que todos os testes se enquadraram em sua avaliação, pois todos obtiveram valores de p não muito notáveis, sendo menor que 0,05 , determinando uma distribuição compatível para a variável aleatória. Dessa forma, a presunção de que os dados são ordenados normalmente é afirmada.

Tabela 5 - Teste de Tendência

\begin{tabular}{cc}
\hline \multicolumn{2}{c}{ Cox-Stuart } \\
\hline Estatística & 21 \\
P-Valor & 0,00 \\
\hline
\end{tabular}

Fonte: Elaborado pelo autor (2018)

No processo do teste de Cox-Stuart, visto na Tabela 5, obteve a garantia de uma estatística $\mathrm{T}=$ 21 e um p-valor $=0.00$. Como a quantia é pequena, a possibilidade de possuir uma medida da estatística de teste é improvável, assegurando a existência de tendência.

Tabela 6 - Modelo linear

\begin{tabular}{cc}
\hline \multicolumn{2}{c}{ Modelo linear } \\
\hline Intercepto & $223.979,58$ \\
$\mathrm{~T}$ & $-280,57$ \\
\hline
\end{tabular}

Fonte: Elaborado pelo autor (2018)

Na Tabela 6, investiga-se a parte contínua da inclinação na série e o seu intercepto (reta regressora que corta o eixo), com o t $=-280,57$. Em outras palavras, ao examinar os valores, a tendência apresentou-se negativa, podendo-se observar em seguida, seu comportamento no gráfico (Figura 5). Como a inclinação é visível, precisa haver uma transformação de dados através das diferenças para torna-la estacionária (uma condição do ARIMA). 
Figura 5 - Análise da Tendência

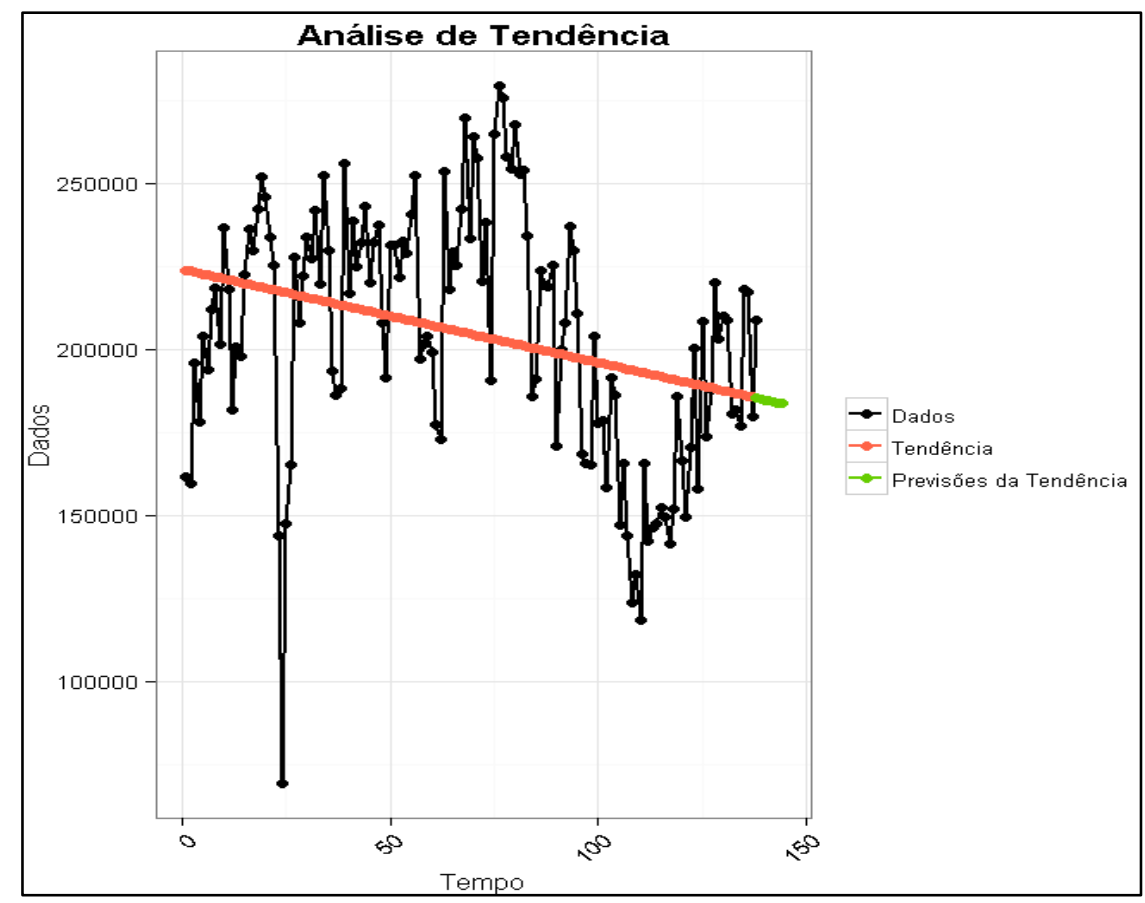

Fonte: Elaborado pelo autor (2018)

Essa divergência é realizável pressupondo defasagens que melhor se condiz ao encadeamento, sendo 1 ou 2 suficientes para chegar a sequência consistente. Uma das maneiras de encontrar o lag certo é por intermédio do teste Ljung-Box estudado adiante na Tabela 9, observando a significância de cada atraso, mas o próprio software selecionado faz todo o procedimento.

Tabela 7 - Teste Sazonal

\begin{tabular}{cc}
\hline \multicolumn{2}{c}{ Teste de Kruskal-Wallis } \\
\hline Estatística & 74,13 \\
P-Valor & $3,05 \mathrm{E}-08$ \\
\hline \multicolumn{2}{l}{ Fonte: Elaborado pelo autor (2018) }
\end{tabular}

Apesar de não exibir um registro visível na série exposta (Figura 2), pode ser aplicada uma hipótese da presença de sazonalidade, uma vez que a produção retrata decadências de ciclos específicos por semestre. Adotando o teste Kruskal-Wallis (Tabela 7), foi concluído que existe sazonalidade, já que o p-valor $=3,05 \mathrm{E}-08$ é pequeno, rejeitando a hipótese nula "Não existência de sazonalidade" com aproveitamento de estatística de 74,13. 
Em suma, a série dispõe de uma distribuição normal, de uma tendência negativa, além de conter um indício de sazonalidade determinística.

Na busca pelo melhor modelo ARIMA utilizou-se a função autoarima do pacote forecast, disponível no software R, critério de informação o BIC e como medidas de acurácias MAPE e MAD. O modelo apropriado foi o SARIMA $(1,0,0)(1,0,0)$. Concluindo que os parâmetros p e P, denotam autoregressividade de ordem 1 e sazonalidade.

Tabela 8 - Medidas de Acurácia

\begin{tabular}{cc}
\hline \multicolumn{2}{c}{ Medidas de Acurácia } \\
\hline MAPE & 15,83 \\
MAD & $28.606,04$ \\
BIC & $2.552,2$ \\
\hline Fonte: Elaborado pelo autor (2018)
\end{tabular}

O modelo com melhor conduta foi examinado através do critério estatístico BIC, revelando um baixo valor de 2.552,2. As métricas exploradas para aperfeiçoar o modelo foi o MAPE e MAD, com valores de $15,83 \%$ e $28.606,04$ respectivamente.

Figura 6 - Histograma

Histogram of model.arima\$residuals

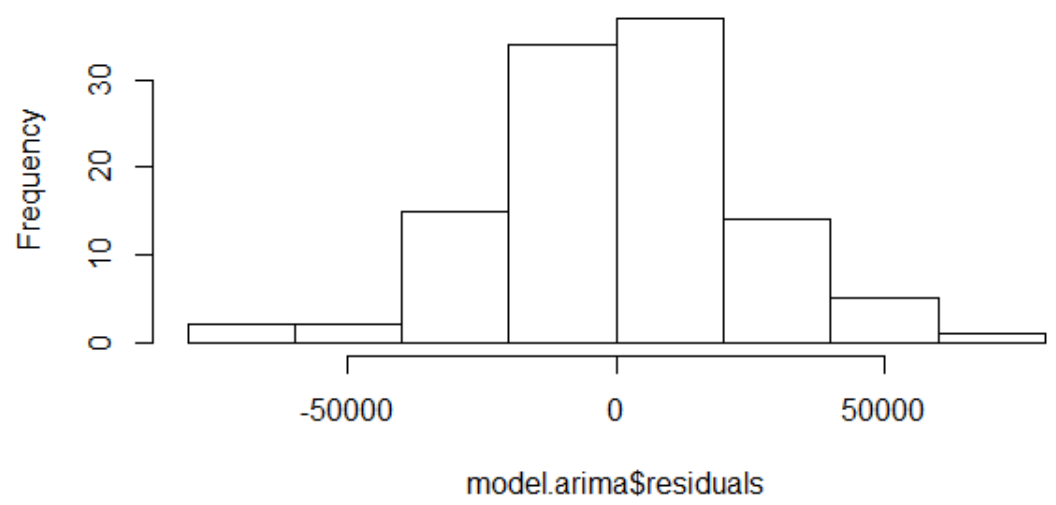

Fonte: Elaborado pelo autor (2018)

$\mathrm{Na}$ análise de resíduos, foi formulado um histograma de um conjunto de dados contínuos (Figura 6), designando que os resíduos possuem, de maneira aproximada, uma distribuição normal, ratificado 
pelo teste de normalidade Shapiro-Wilk (Tabela 9), com o propósito de modelar a série, além de não exibir desvios sistemáticos.

Tabela 9 - Testes No Processo de Resíduos

\begin{tabular}{ccc}
\hline Testes & Estatísticas & P-valores \\
\hline Shapiro - Wilk & 0,98 & 0,13 \\
Ljung - Box & 0,81 & 0,36
\end{tabular}

Fonte: Elaborado pelo autor (2018)

A tabela acima demonstra que os resíduos são independentes, ao ver que o $p$ é maior que o nível de significância $(0,05)$, ou seja, o modelo atende à suposição, se ajustando aos dados e facilitando na interpretação dos resultados.

Figura 7 - Correlogramas dos Resíduos
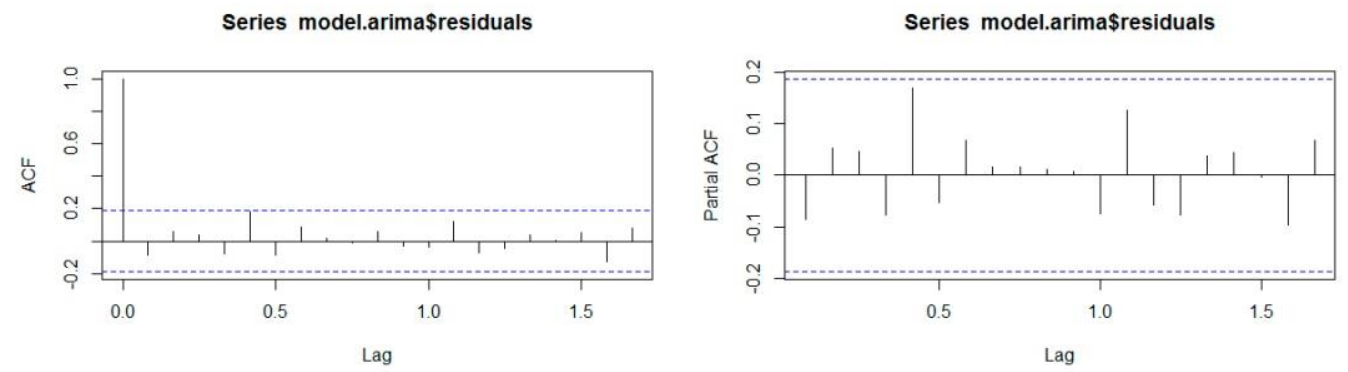

Fonte: Elaborado pelo autor (2018)

Com a Figura das Autocorrelações após o retiramento dos resíduos (Figura 7), pode-se finalizar que o modelo da série simbolizou em um bom amoldamento, pois os mesmos não são autocorrelacionados.

Figura 8: Gráfico do modelo ARIMA

\section{Forecasts from ARIMA $(1,0,0)(1,0,0)[12]$ with non-zero mean}

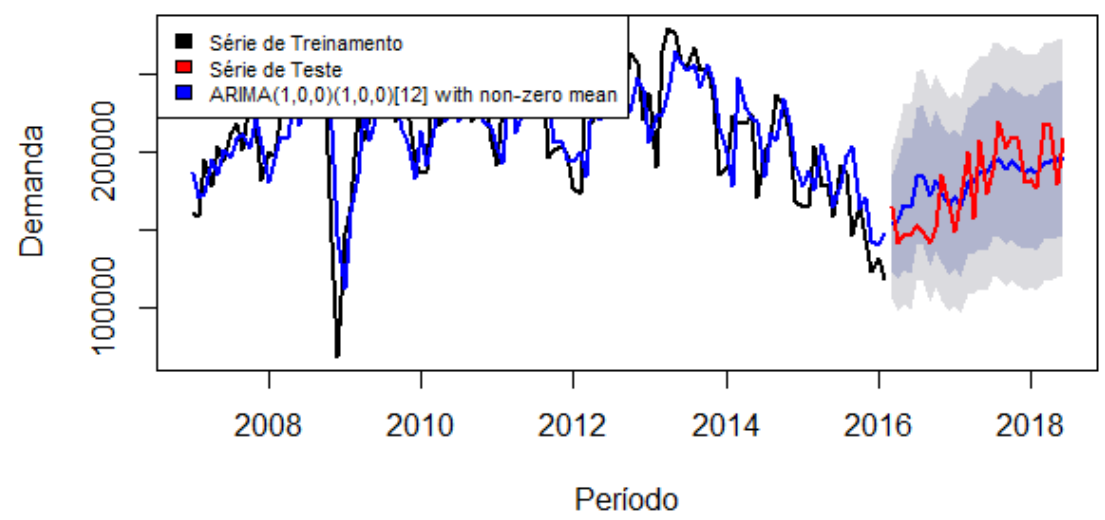

Fonte: Elaborado pelo autor (2018) 
A Figura 8 representa os dados para treinamento do modelo (criação do modelo), usando 80\% da série (janeiro de 2007 a fevereiro de 2016) e os $20 \%$ restantes foram empregados na série de teste e, em seguida houve a previsão, assegurando o andamento da série de forma conveniente.

Figura 7: Gráfico Real de Previsão

Forecasts from ARIMA $(1,0,0)(1,0,0)[12]$ with non-zero mean

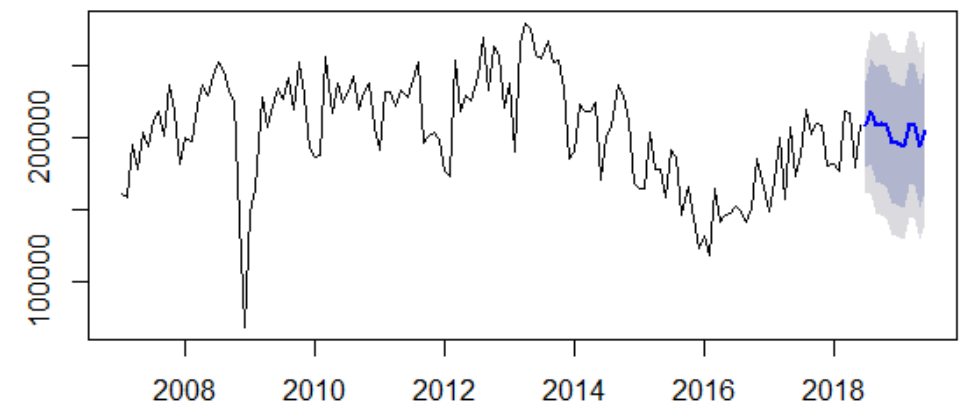

Fonte: Elaborado pelo autor (2018)

Complementando, a Figura 7 indica um esboço da montante real de produção, ligado a outros valores ajustados durante as etapas. No entanto, as previsões concebidas pelo modelo, na área azul, viabilizam suposições coerentes relacionados às produções futuras, verificando o não indício de tendência. As previsões previstas são observadas na Tabela 10, no segundo semestre de 2018.

Tabela 10: Previsão do período jul/18 à dez/18

\begin{tabular}{cccc}
\hline Período & Previsão & Limite mínimo & Limite máximo \\
\hline jul/18 & $209.204,30$ & 162959,00 & 255449,70 \\
\hline ago/18 & $218.262,60$ & 161876,40 & 274648,90 \\
set/18 & $209.059,50$ & 148347,80 & 269771,20 \\
out/18 & $210.002,80$ & 147294,00 & 272711,70 \\
nov/18 & $208.188,50$ & 144530,40 & 271846,60 \\
dez/18 & $196.300,50$ & 132185,50 & 260415,50 \\
\hline
\end{tabular}

Fonte: Elaborado pelo autor (2018) 


\section{Considerações Finais}

Os modelos de Box e Jenkins indicam uma preferência propensa para estudos com base na previsão de produção de automóveis. Com a ampliação da comercialização de veículos, é indispensável aproveitar modelos convenientes à previsão, posto que evidência frequente instabilidade em seu consumo. Diante disso, as previsões concebidas são aceitáveis para o beneficiamento de cálculos mais precisos das empresas incluídas no ramo.

Dentre os modelos reconhecidos, o que exibiu conveniente para a série foi o modelo SARIMA $(1,0,0)(1,0,0)$. O mesmo envolveu o mínimo de parâmetros possíveis para explicar o desempenho da variável em análise. É importante esclarecer uma complicação no início, pois após plotar a série, analisou-se que não era estacionária, obrigando realizar alguns ajustes para atingir o estado do modelo.

A diferenciação e média móvel não foram apresentadas no modelo de ajuste. Os valores de pico aparecidos foram causados por conta da sazonalidade descoberta nas funções de autocorrelações. No ramo de automóveis há poucas utilizações do modelo, finalizando a existência da cooperação do artigo para estudos futuros na área e favorecendo na organização de fábricas quanto a pontos estratégicos.

Além de ser uma poderosa ferramenta para previsões de curto prazo, ainda apresenta algumas desvantagens como a não existência de procedimentos simples para ser efetuado o cálculo, requer experiência mesmo com sua utilidade espontânea e oferece vários modelos tornando-o mais complicado.

Algumas sugestões podem ser sugeridas, como a aplicação de outros modelos para o melhor ajuste de previsões no setor, pôr em prática a metodologia utilizada para viabilizar rendimentos em outros segmentos, principalmente econômicos. Ainda se pode adicionar uma complementação para incluir variáveis esclarecidas ao modelo do estudo, com o fim de alcançar ganhos expressivos nos prognósticos.

\section{Referências}

AMORIM, M. R. B. Modelagem em séries temporais aplicados a dados de temperatura máxima na cidade de Campina Grande-PB. 2014.Disponível em: http://dspace.bc.uepb.edu.br/jspui/handle/123456789/4125 > Acesso em: 06 de ago. 2018.

ASTOLPHI, M.V. C. et al. A inserção da indústria automobilística brasileira nas cadeias globais de valor: uma análise do período 2000-2017. 2018. Disponível em: < http://repositorio.ufu.br/handle/123456789/22119.> Acesso em: 06 de ago. 2018. 
BOWERSOX, D. J. Logística Empresarial: o processo de integração da cadeia de suprimentos. 1.ed. São Paulo; Atlas, 2010. Acesso em: 07 ago. 2018.

BOX, G. E. P; JENKINS, G. M. (1976). Time series analysis: forecasting and control, 2nd ed. San Francisco. Holden-Day. Acesso em: 08 de ago. 2018.

CAMPOS, P. A.C.; CLEMENTE, A.; DE CORDEIRO, A. A.L. Aplicação do modelo ARIMA para previsão do preço do frango inteiro resfriado no grande atacado do estado de São Paulo. In: Anais do Congresso Brasileiro de Custos-ABC. 2006.2 Disponível em: <https://anaiscbc.emnuvens.com.br/anais/article/view/1871> Acesso em: 10 ago. 2018.

CARLIN, B. P.; LOUIS, T. A. Empirical Bayes: Past, present and future. Journal of the American Statistical Association, v. 95, n. 452, p. 1286-1289, 2000. Disponível em: $<$ https://amstat.tandfonline.com/doi/abs/10.1080/01621459.2000.10474331?journalCode=uasa20\#.W49ibhKhPY> Acesso em: 16 set. 2018.

CAS, C. G. Aplicação do Modelo ARIMA para Previsão do Preço da Commodity Milho. Revista GEPROS, v. 13, n. 1, p. 263, 2018. Disponível em: < https://revista.feb.unesp.br/index.php/gepros/article/view/2040 > Acesso em: 08 de ago. 2018.

CERETTA, P. S.; RIGHI, P. B.; SCHLENDER, S. G. Previsão do preço da soja: uma comparação entre os modelos ARIMA e redes neurais artificiais. Informações Econômicas, v. 40, n. 9, p. 15-27, 2010. Disponível em: < ftp://ftp.sp.gov.br/ftpiea/publicacoes/ie/2010/tec2-0910.pdf> Acesso em: 15 de ago. 2018.

CRYER, J. D.; CHAN, K. Time Series Analysis: With Applications in R. 2 ed. New York: Springer, 2008. Acesso em: 22 de set. 2018.

DE SALES, J. P. et al. Utilização do método de box-jenkins para modelagem e previsão da produção brasileira de autoveículos. Latin American Journal of Business Management, v. 9, n. 1, 2018. Disponível em: <http://lajbm.net/index.php/journal/article/view/462> Acesso em: 13 de ago. 2018.

DE SENNA, V. et al. Análise exploratória e aplicação da metodologia box e jenkins na modelagem e previsão de fluxo de caixa de empresa na área gráfica. Revista ESPACIOS| Vol. 35 (No 10) Año 2014, 2014. Disponível em: <http://www.revistaespacios.com/a14v35n10/14351010.html> Acesso em: 14 de set. 2018.

EHLERS, R. Análise de séries temporais: Relatório Técnico. Säo Paulo: USP, 2009

FAVA, V. Manual de econometria. In: VASCONCELOS, M. A. S.; D. São Paulo: Editora Atlas, 2000. Acesso em: 29 de set. 2018.

FELIPE, I. J. dos S. Aplicação de modelos ARIMA em séries de preços de soja no norte do Paraná. Tekhne e Logos, v. 3, n. 3, p. 16-32, 2012. Disponível em: http://www.fatecbt.edu.br/seer/index.php/tl/article/view/150> Acesso em: 03 de set. 2018.

FERRO, W. A. et al. Previsão de demanda em indústrias de eletrodomésticos por meio da integração de métodos quantitativos e qualitativos. 2018. Dissertação de Mestrado. Universidade Tecnológica Federal do Paraná. Disponível em; < http://repositorio.utfpr.edu.br:8080/jspui/handle/1/3058 > Acesso em: 05 de out. 2018.

FIGUEIREDO, N. M.; BLANCO, C. J. C.. Simulação de Vazões e Níveis de Água Médios Mensais para o Rio Tapajós Usando Modelos ARIMA. Revista Brasileira de Recursos Hídricos, v. 19, n. 3, p. 111-126, 2014. Disponível em: https://www.researchgate.net/profile/Claudio_Blanco/publication/278609243_Simulacao_de_Vazoes_e_Ni veis_de_Agua_Medios_Mensais_para_o_Rio_Tapajos_Usando_Modelos_ARIMA/links/55816e3008ae607 
ddc33bc88/Simulacao-de-Vazoes-e-Niveis-de-Agua-Medios-Mensais-para-o-Rio-Tapajos-UsandoModelos-ARIMA.pdf.> Acesso em: 20 ago. 2018.

FLIGENSPAN, F. B.; CALANDRO, Maria Lucrécia. Novos investimentos na indústria automobilística brasileira: o caso gaúcho. Indicadores Econômicos FEE, v. 30, n. 3, p. 5-30, 2002. Disponível em: < file:///C:/Users/S\%C3\%A9fora/Desktop/TCC\%20ARIMA/1403-5868-1-PB.pdf> Acesso em: 16 de out. 2018.

GOMES, F. C. Os modelos Arima e a abordagem de Box-Jenkins uma aplicação na previsão do IBOVESPA a curtíssimo prazo. Revista de Administração de Empresas, v. 29, n. 2, p. 63-70, 1989. Disponível em: < http://www.scielo.br/scielo.php?pid=S0034-75901989000200006\&script=sci_arttext\&tlng=pt $>$ Acesso em: 22 de set. 2018.

GUJARATI, D. N.; PORTER, Dawn C. Econometria Básica-5. Amgh Editora, 2011. Acesso em: 17 de ago. 2018.

KITAGAWA, G. Introduction to Time Series Modeling. Tokyo. Chapman \& Hall/CRC, 2010. Acesso em: 16 de ago. 2018.

LATORRE, M. do R. D. de et al. Análise de séries temporais em epidemiologia: uma introdução sobre os aspectos metodológicos. Revista Brasileira de Epidemiologia, v. 4, p. 145-152, 2001. Disponível em: < https://www.scielosp.org/article/rbepid/2001.v4n3/145-152/pt/> Acesso em: 03 de set. 2018.

LEE, C.; KO, C.. Short-term load forecasting using lifting scheme and ARIMA models. Expert Systems with Applications, v. 38, p. 5902-5911, 2011. Disponível em: < https://www.sciencedirect.com/science/article/pii/S0957417410012704> Acesso em: 18 de ago. 2018.

LEITE, D. A. N. de O. et al. Avaliação dos parâmetros do índice de qualidade de água segundo o modelo ARIMA. Holos Environment, p. 24-39, 2013. Disponível em: < https://repositorio.unesp.br/handle/11449/137288> Acesso em: 01 de out. 2018.

LOURENÇO, I. dos S.; NASCIMENTO, L. de O. Métodos de previsão aplicados a uma série de volume de produção de caminhões. 2012 Disponível em: < http://www.ufjf.br/estatistica/files/2014/10/ME_2012_07_Isaac-dos-Santos Louren\%C3\%A7o-e-Luis-deOliveira-Nascimento.pdf> Acesso em: 01 de set. 2018.

LUCAS, E. W. M. et al. Modelagem hidrológica determinística e estocástica aplicada à região hidrográfica do Xingu-Pará. Revista Brasileira de Meteorologia, v. 24, n. 3, p. 308-322, 2009. Disponível em; < http://www.scielo.br/pdf/rbmet/v24n3/a05v24n3> Acesso em: 04 de out. 2018.

MAKRIDAKIS, S.; WHEELWRIGHT, S.; HYNDMAN, R. Forecasting: Methods and Applications, 3rd ed.; JohnWiley \& Sons: New York, NY, USA, 1998. Acesso em: 05 de set. 2018.

MARENGUE, R. H. Um estudo sobre a aplicação do método ARIMA para a previsão das movimentações de veículos nos portos de Paranaguá e Santos. 2017. Trabalho de Conclusão de Curso. Universidade Tecnológica Federal do Paraná. Disponível em; < http://repositorio.roca.utfpr.edu.br/jspui/handle/1/8635 > Acesso em: 12 de out. 2018.

MARTIN, A. C. et al. Análise de séries temporais para previsão da evolução do número de automóveis no Município de Joinville. Revista ESPACIOS| Vol. 37 ( $\mathrm{N}^{\circ}$ 06) Año 2016, 2016. Disponível em: < http://www.revistaespacios.com/a16v37n06/16370629.html> Acesso em: 17 de set. 2018. 
MONIZ, A. Futuros da indústria automóvel: Qual a sua importância para a definição do produto, modelos de produção e estratégias de mobilidade?. 2007. Disponível em: 〈https://mpra.ub.uni-muenchen.de/5939/> Acesso em: 18 de out. 2018.

MORETTIN, P. A.; TOLOI, C. M. de C. Modelos para previsão de séries temporais. Instituto de matematica pura e aplicada, 1981. Acesso em: 19 de out. 2018.

MORETTIN, P.; TOLOI, C. M. C. Análise de séries temporais. São Paulo: Edgard Blucher, 2004. 535p. Acesso em: 26 de set. 2018.

MOURA, G. C. de. Previsão custo unitário por meio de modelos de previsão da classe geral arima. 2018. Disponível em: < http://bibliodigital.unijui.edu.br:8080/xmlui/handle/123456789/5077> Acesso em: 23 de ago. 2018.

PELLEGRINI, F. R. Metodologia para implementação de sistemas de previsão de demanda. Mestrado em Engenharia de Produção-Departamento de Engenharia de Produção e Transportes. Porto AlegreUniversidade Federal do Rio Grande do Sul, 2000. Disponível em; < http://www.producao.ufrgs.br/arquivos/publicacoes/Fernando\%20R\%20Pellegrini.pdf $>$ Acesso em: 14 de ago. 2018.

PINDYCK, R. S.; RUBINFELD, D. L. Economia-Modelo e Previsões. Tradução da, 2004. Acesso em: 17 de set. 2018.

PRODANOV, C. C.; FREITAS, E. C. de. Metodologia do trabalho científico: métodos e técnicas da pesquisa e do trabalho acadêmico-2a Edição. Editora Feevale, 2013. Acesso em: 15 de out. 2018.

RAJAPRASAD, S. V. S. Prediction of fatal accidents in Indian factories based on ARIMA. Production Engineering Archives, v. 18, p. 24--30, 2018. Disponível em: < http://yadda.icm.edu.pl/yadda/element/bwmeta1 .element.baztech-cc7726e7-5961-47ad-929e6c3e78e16158.> Acesso em: 03 de out. 2018.

RIBEIRO, L. C.; PAULA, A. V. de. Previsão de população através dos modelos arima de Box e Jenkins: um exercício para Brasil. Anais, 2016. Disponível em: < file:///C:/Users/S\%C3\%A9fora/Desktop/TCC\%20ARIMA/1067-3085-1-PB\%20(1).pdf> Acesso em: 14 de ago. 2018.

SÁFADI, T.. Uso de séries temporais na análise de vazão de água na represa de Furnas. Ciência e Agrotecnologia, v. 28, n. 1, p. 142-148, 2004. Disponível em: < https://www.researchgate.net/profile/Thelma_Safadi/publication/273364375_Uso_de_series_temporais_na _analise_de_vazao_de_agua_na_represa_de_furnas/links/56b086cf08ae9c1968b6e17a/Uso-de-seriestemporais-na-analise-de-vazao-de-agua-na-represa-de-furnas.pdf > Acesso em: 02 de set. 2018.

SANTILI, M. A. Métodos de previsão auto-regressivo aplicado a uma série de volume de produção de caminhões. $2015 . \quad$ Disponível em: https://repositorio.unesp.br/bitstream/handle/11449/139106/000865443.pdf?sequence=1> Acesso em: 24 de set. 2018.

SANTOS, C. dos. Previsão de custos de um condomínio de apartamentos utilizando a metodologia de box e jenkins para séries temporais. Orbis Latina, v. 7, n. 4, p. 74-90, 2018. Disponível em: <https://revistas.unila.edu.br/orbis/article/view/919/890> Acesso em: 02 de out. 2018. 
SANTOS, V. Séries temporais ARIMA. 2014. Disponível em: <http://www.ufpa.br/heliton/arquivos/aplicada/seminarios/M1_08_ARIMA_Verena.pdf> Acesso em: 04 de out. 2018.

SÁ-SILVA, J. R.; ALMEIDA, C. D. de; GUINDANI, Joel Felipe. Pesquisa documental: pistas teóricas e metodológicas. Revista brasileira de história \& ciências sociais, v. 1, n. 1, 2009. Disponível em; < https://www.rbhcs.com/rbhcs/article/view/6 > Acesso em: 10 de out. 2018.

SEVERINO, A. J. Metodologia do trabalho científico. Cortez editora, 2017. Acesso em: 01 de out. 2018.

SILVA, A. F.. Definição de um modelo de previsão das vendas da rede varejista alphabeto. 2008 . Tese de Doutorado. UNIVERSIDADE FEDERAL DE JUIZ DE FORA. Disponível em: < http://www.ufff.br/ep/files/2014/07/2008_3_Andr\%C3\%A9.pdf> Acesso em: 24 de ago. 2018

SILVA, L. da. Análise da aplicação do modelo ARIMA: estudo em uma instituição federal de ensino superior. $2017 . \quad$ Disponível em: https://repositorio.ufsm.br/bitstream/handle/1/11684/SILVA_Luiza_Da.pdf?sequence=1\&isAllowed=y $>$

Acesso em: 18 de set. 2018.

SLACK, N.; JONES, A. B.; JOHNSTON; R. Administração da produção. 4 ed. São Paulo: Atlas, 2015. Acesso em: 20 de set. 2018.

SOKI, J. R. Métodos de previsão da taxa de inflação de Angola. 2018. Tese de Doutorado. Instituto Superior de Economia e Gestão. Disponível em: < https://www.repository.utl.pt/handle/10400.5/15560 > Acesso em: 22 de set. 2018.

SOUZA, F. M. Modelos Box \& Jenkins aplicados a previsão de demanda de leitos hospitalares. Programa de Pós-Graduação em Estatística e Modelagem Quantitativa, Universidade Federal de Santa Maria (UFSM): Santa Maria, Brazil, 2006. Disponível em: < http://w3.ufsm.br/adriano/mon/fm.pdf > Acesso em: 03 de out. 2018.

SOUZA, F. M.; SOUZA, A. M.; LOPES, L. F. D.. Previsão da demanda de leitos hospitalares por meio da análise de Série Temporais. Ciência e Natura, v. 31, n. 1, p. 33-47, 2009. Disponível em: < https://periodicos.ufsm.br/index.php/cienciaenatura/article/view/9904.> Acesso em: 24 de set. 2018.

TOLEDO, G. L.; MARTINS, G. de A.; FONSECA, J. S. da. Estatística aplicada. São Paulo: Atlas, 1985. Acesso em: 09 de ago. 2018.

TORRES, R. L.; CARIO, S. A. F. A governança da cadeia global de valor na indústria automobilística: um estudo de caso. Revista Econômica, v. 14, n. 1, 2013. Disponível em: < http://www.revistaeconomica.uff.br/index.php/revistaeconomica/article/view/40> Acesso em: 05 de ago. 2018.

TUBINO, D. F. Planejamento e controle da produção: teoria e prática / Dalvio Ferrari Tubino. - 3. ed. São Paulo: Atlas, 2017. Acesso em: 04 de set. 2018.

WALTER, O. M. F. C. et al. Aplicação de um modelo SARIMA na previsão de vendas de motocicletas. Exacta, v. 11, n. 1, 2013. Disponível em: < http://www.redalyc.org/html/810/81027458007/> Acesso em: 14 de ago. 2018.

WALTER, O. M. F. C. et al. Previsão de vendas para um modelo de automóvel popular com a metodologia Box e Jenkins. X SEPROSUL-Semana De Engenharia De Produção Sul-Americana. Chile, Santiago, $\quad$ p. $\quad 1-10, \quad 2010 . \quad$ Disponível $\quad$ em:

1096 Id on Line Rev. Mult. Psic. V.12, N. 42, p. 1073-1097, 2018 - ISSN 1981-1179 Edição eletrônica em http://idonline.emnuvens.com.br/id 
http://previsaosimples.pbworks.com/w/file/fetch/67434559/039\%20BOX\%26JENK.pdf> Acesso em: 13 de ago. 2018.

WERNER, L.; RIBEIRO, J. L. D.. Previsão de demanda: uma aplicação dos modelos Box-Jenkins na área de assistência técnica de computadores pessoais. Gestão e produção. São Carlos, SP. Vol. 10, n. 1 (abr. 2003), p. 47-67, 2003. Disponível em: < http://www.scielo.br/pdf/gp/v10n1/a05v10n1> Acesso em: 06 de set. 2018 .

ZUCOLOTO, A. C.; GIAROLA, L. T. P.; ROCHA, R. C. da. Modelagem da Exportação Brasileira de Automóveis. Matemática e Estatística em Foco, v. 6, n. 1, p. 12-23. Disponível em: $<$ http://www.seer.ufu.br/index.php/matematicaeestatisticaemfoco/article/view/39080> Acesso em: 08 de set. 2018.

\section{Como citar este artigo (Formato ABNT):}

PEREIRA, Séfora Laissa Alcântara; LIMA, José Eduardo de Carvalho. Aplicação do Modelo Box-Jenkins na Previsão da Produção de Automóveis. Id on Line Rev.Mult. Psic., 2018, vol.12, n.42, p. 1073-1097, 2018. ISSN: 1981-1179.

Recebido: 28/10/2018;

Aceito: $29 / 10 / 2018$ 